\title{
LAS ACTUALES PROPUESTAS Y DESAFÍOS EN EDUCACIÓN: EL CASO ECUATORIANO
}

\author{
EDGAR ISCH LÓPEZ*
}

\begin{abstract}
RESUMEN: El presente artículo busca explicar analíticamente el actual escenario de intereses conflictivos en Ecuador, referidos a la estructura y principales objetivos del sistema educativo a escala nacional. Este análisis demuestra que los cambios en el interior de la educación durante los últimos cuatro años, correspondientes al gobierno de Rafael Correa, no tienen una clara política estatal y no responden a una concepción nacionalista. Esas contraposiciones se expresaron principalmente al momento de tomar posición ante la nueva ley de educación, que fue aprobada en este año. Sin embargo, hay importantes cambios en orden a financiar las políticas sociales y, desde la aprobación del Plan Decenal de Educación en 2006, se han implementado reformas que están transformando la situación en el interior de los establecimientos educativos en el Ecuador.
\end{abstract}

Palabras clave: Política de educación. Educación Siglo xxi. Equador. Rafael Correa. Reforma en educación.

\section{Current proposals ANd CHALlenges in EDUCATION: THE ECUADORIAN CASE}

\begin{abstract}
This paper seeks to explain analytically the present scenario of conflicting interests in Ecuador regarding the structure and main objectives of the education system at the national level. Its analysis shows that the changes within education in Ecuador these last four years, i.e., during the Correa administration, do not present a clear state policy or respond to a nationalist conception. Such discrepancies were mainly expressed when it came to taking a stance on the new educational law, approved this year. However, there are important changes in order to finance social policies and after the Decennial Plan of National Education was approved in 2006, reforms have been implemented to transform the situation inside Ecuadorian schools.
\end{abstract}

Key words: Education policies. Education in the $21^{\text {st }}$ century. Ecuador. Rafael Correa. Education reform.

Investigador educativo de la Red Social Para La Educación Pública en las Américas (SEPA) y ex-ministro de Ambiente del Ecuador. E-mail: edgarisch@yahoo.com 


\section{Propositions et défis ACTUELS EN ÉdUCATION:}

\section{LE CAS ÉQUATORIEN}

RÉSUMÉ: cet article tente d'expliquer analytiquement le présent scénario d'intérêts contradictoires en Équateur pour ce qui est de la structure et des principaux objectifs du système éducationnel au niveau national. Son analyse montre que les changements ayant pris place au sein de l'éducation en Équateur ces quatre dernières années, soit pendant le gouvernement de Rafael Correa, ne suivent aucune politique d'état claire ni ne répondent à une conception nationaliste. Ces divergences se sont clairement manifestées lorsqu'il a fallu prendre position quant à la nouvelle loi sur l'éducation, approuvée cette année. Néanmoins, des améliorations on été apportées en matière de financement des politiques sociales et, depuis que le Plan décennal d'Éducation nationale a été approuvé en 2006, des réformes ont été mises en œuvre pour transformer la situation à l'intérieur les établissements scolaires équatoriens.

Mots-clés: Politiques d'éducation. Éducation au xxI ${ }^{\mathrm{e}}$ siècle. Équateur. Rafael Correa. Réforme de l'enseignement.

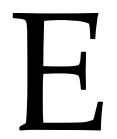

1 presidente Rafael Correa toma posesión en enero del año 2007, luego de una campaña en la cual paulatinamente fue radicalizando su discurso y asumiendo las propuestas que los distintos sectores y organizaciones sociales de carácter popular habían impulsado a lo largo de toda la lucha contra el neoliberalismo. La acción social había derrocado a tres gobiernos e impidió, a lo largo de estos años, la aplicación de la totalidad de las propuestas neoliberales y, particularmente en el caso educativo, ello significó impedir reformas curriculares expresamente destinadas a segregar a la población de acuerdo con el criterio clasista sobre cuál alcance educativo podría tener cada estudiante ecuatoriano a lo largo de su vida. Así, se detuvo la propuesta de "educación para la supervivencia" (1995), el currículo basado en la pedagogía conceptual y que diferenciaba tres tipos de trabajadores (1996), la municipalización insistentemente propuesta, la imposición de la educación religiosa en las escuelas públicas (1995-1996); la conformación de escuelas charter (propuesta de los industriales a lo largo de los años 90); entre otros.

El gobierno actual, resultante de ese impulso transformador, ha sido calificado como de "revolución ciudadana". Analizar las propuestas educativas en este período (2007-2011) implica no sólo considerar aquellas planteadas desde el gobierno, sino también otras que reflejan determinados intereses de clase y que permitirán comprender el grado de avance real que los cambios educativos han tenido y los impactos iniciales de los mismos.

Este artículo pretende enfrentar dicho análisis centrando la atención en la educación general básica y bachillerato, sin hacer mayor referencia a los procesos vinculados a la educación superior, los mismos que tienen particularidades cuya interpretación no sería posible en este espacio. 


\section{Antecedentes}

Ecuador se caracterizó por una alta valoración de la escuela pública hasta pasados los años 60 del siglo xx, logrando tener uno de los más altos porcentajes de cobertura en América Latina. Con el impulso de las políticas neoliberales abiertamente desde 1982, no logró los propósitos señalados en los planes y programas educativos al grado de que, por ejemplo, en las pruebas de conocimientos estudiantiles en las áreas básicas realizadas bajo el nombre de "Aprendo" en los años 1996 y 2000, existe un deterioro en el puntaje estudiantil a pesar del desarrollo de programas auspiciados con la deuda externa (Aprendo, 1998; 2000).

La reducción en el puntaje de los estudiantes hizo que al final de los años 90 se tenga un promedio nacional de $8 / 20$ puntos en lenguaje y $7 / 20$ en matemáticas, para el nivel escolar (Aprendo, 2000). Por supuesto, la calidad a la que se hace referencia en esos proyectos está ligada a la utilidad del "producto, no en virtud de sus características objetivas, sino de la percepción subjetiva del cliente" (Estévez Pérez, 2010, p. 22).

Esto significó que se hizo mucho más en el orden ideológico para permitir procesos de privatización y de segregación escolar antes que, para atender las necesidades de los sectores más amplios de la población. El lenguaje neoliberal insertado en el proceso educativo, implicó importantes cambios en las concepciones educativas de los educadores y los padres de familia, que cada vez se acercaron más a una perspectiva empresarial y, se alejaron de una comprensión pedagógica del proceso de enseñanza aprendizaje (Isch López, 2001). En términos generales, aquello implicó rupturas y debilitamiento de los sectores educativos para enfrentar la nueva ola que venía con grandes recursos a través de proyectos internacionales.

Las reformas educativas basadas en el recetario de los Bancos Mundial e Interamericano, tuvieron las características propias de los procesos impuestos desde fuera del país y de la realidad de las instituciones educativas, con la pretensión de transformar sin consultar. Fueron reformas tecnocráticas, alejadas de la realidad, que consideraron a la educación como un sector aislado de otras responsabilidades estatales, pero ubicada entre las propuestas generales de una descentralización administrativa pero no democratizadora y de la focalización, que permitió justificar la separación entre la educación de los más pobres frente a la educación de las clases acomodadas. De esta manera, puede decirse que la intencionalidad de fondo fue impulsar educaciones diferentes para clases sociales diferentes.

Los procesos de capacitación masiva dirigidos a los docentes e incluso la publicación de textos escolares gratuitos para la educación rural, no lograron resultados beneficiosos porque en general el sistema educativo estuvo fragmentado y se 
volvería un decir habitual que cada plantel educativo se convertía en una isla sin conexión con los demás.

En síntesis, la crisis educativa se hizo más evidente y desde sus distintos sectores se presentaron análisis y propuestas (por ejemplo, FLACsO, 2008; CARE, 2008; UNE, 2008), aunque parte de esos documentos insistían en la lógica neoliberal. Desde los sectores empresariales, los gobiernos y la educación privada se procuró responsabilizar exclusivamente al magisterio por la crisis educativa, lo cual no sólo que forma parte de la retórica neoliberal (Gentili, 1996), sino que además pretende ocultar que la crisis es resultado de los proyectos educativos impulsados en esos años y que, por tanto la crisis correspondía precisamente a la aplicación del neoliberalismo educativo, que fue impuesto con la contraposición del sindicato de maestros (la Unión Nacional de Educadores, UNE) y de otros importantes sectores académicos y de la sociedad civil.

En el caso ecuatoriano, las políticas educativas de los años 90 fueron impuestas de manera principal a través de los proyectos financiados con créditos de la deuda externa. La Comisión para la Auditoría Integral del Crédito Público (Isch López, 2008) incluyó en su trabajo los créditos educativos que fueron determinantes en las políticas educativas, por encima del propio Ministerio de Educación que, popularmente, pasó a ser llamado el "ministerio pobre", frente al "ministerio rico", que era cualquiera de esos programas.

El análisis demostró la imposición de las políticas neoliberales afectando de múltiple manera al derecho humano a la educación, provocando cambios al margen de los intereses nacionales y de las leyes vigentes, generando un traspaso de competencias del estado al sector privado o a los usuarios mediante mecanismos de pago $\mathrm{y}$, finalmente, sin generar una educación de mejor calidad, lo cual de hecho está confirmado en documentos de los mismos bancos gestores de estos proyectos (Isch López, 2008).

En las conclusiones de dicho estudio, se remarcaron los efectos negativos de estos créditos y los proyectos relacionados, al mismo tiempo que se remarcó que: "salir del peso de la deuda significa también salir de la aplicación del neoliberalismo en educación, reexaminar las reformas administrativas y educativas impuestas desde esta óptica y desde los bancos multilaterales, buscar una educación que responda nuestra realidad (...)" (Isch L., 2008, p. 26). Lamentablemente, las autoridades ministeriales del gobierno actual no han cuestionado dichos proyectos, lo cual puede ser comprensible si se considera que el funcionario de más importancia en el área educativa en el gobierno de Rafael Correa ha sido el exministro Raúl Vallejo (ministro entre enero 2007 y abril de 2010), quién había ejercido funciones de Ministro de Educación (1991 y 1992) en el gobierno que impulsó este tipo de proyectos, encabezado por Rodrigo Borja, así como lo fue en el gobierno de Alfredo Palacio (2005-2006). 
Algunos datos indicadores de esta crisis, los resumió unicEF (2006), demostrando los altos niveles de abandono escolar, graves condiciones de dos de cada diez escuelas, el pluriempleo docente y el descenso continuo del presupuesto educativo desde el 5,4\% del piв en 1981, hasta el 1,8\% del piв en el año 2000. Del total de 1' 657.963 estudiantes de las escuelas primarias para el año 1999-2000, solo 356.837 recibieron textos escolares, en su mayoría desde los gobiernos locales y no del Estado central.

Las reformas, si bien habían propuesto el alineamiento con la corriente pedagógica constructivista, no lograron superar viejas prácticas tradicionales, maltratadoras y descontextualizadas. La demanda de atención integral a los niños y niñas posibilitó el desarrollo de un programa de desayunos y almuerzos para la primaria bajo el nombre de Programa de Alimentación Escolar (PAE), que en el 2000 atendió a cerca de 1 millón y medio de estudiantes con un presupuesto reducido que bajó de \$ 30,700.000 en el 2003 a 16 millones en el 2004 (Luna Tamayo, 2006).

\section{La promesa de la revolución educativa}

La lucha social por la educación permitió el desarrollo de tres Consultas Nacionales "Educación Siglo xxI", en las cuales se lograron importantes acuerdos con la participación de los más diversos sectores de la sociedad ecuatoriana. La Primera Consulta (1992) estableció las "Bases del Acuerdo Nacional", que se complementó en la Segunda Consulta, realizada en 1996. Los acuerdos alcanzados, sin embargo, no fueron considerados por los distintos gobiernos, lo que conduce a la realización de una Tercera Consulta que fue menos ambiciosa y procuró ser más pragmática en el establecimiento de metas puntuales.

El debate y la demanda de una atención seria a la educación condujo, por primera vez en la historia nacional, a un Plan Decenal 2006-2015 (Ministerio de Educación y Cultura, 2006), que consideró tanto las tres consultas anteriores cuanto los compromisos internacionales asumidos por el Ecuador. Las políticas fundamentales de ese plan son:

1. Universalización de la educación inicial de cero a cinco años.

2. Universalización de la Educación General Básica de primero a décimo años.

3. Incremento de la matrícula del bachillerato hasta alcanzar al menos el $75 \%$ de la población en la edad correspondiente.

4. Erradicación del analfabetismo y fortalecimiento de la educación continua para adultos. 
5. Mejoramiento de la infraestructura física y el equipamiento de las instituciones educativas.

6. Mejoramiento de la calidad y equidad de la educación e implementación de un sistema nacional de evaluación y rendición social de cuentas del sistema educativo.

7. Revalorización de la profesión docente y mejoramiento de la formación inicial, capacitación permanente, condiciones de trabajo y calidad de vida.

8. Aumento del $0.5 \%$ anual en la participación del sector educativo en el Producto Interno Bruto (PIB) hasta el año 2012, o hasta alcanzar al menos del $6 \%$ del PIB.

Estas políticas fueron aprobadas mediante consulta popular el 26 de noviembre de 2006, contando con el apoyo de todos los sectores educativos y la mayor parte de organizaciones sociales, aunque parte de los partidos identificados con la derecha política se abstuvieron de promover el voto ante estas propuestas. El Plan Decenal fue aprobado por más del $66 \%$ de los votantes y un voto negativo de menos del $8 \%$.

Al iniciar el gobierno Rafael Correa con este mandato popular y haber ratificado al ministro de educación, este Plan Decenal se convirtió, en buena medida en la propuesta educativa del gobierno, sin embargo en la página web del Ministerio de Educción solo está el Plan con los logros de 2006 y metas del 2007, sin informes anuales de cumplimiento, tal como el mismo Plan dispone. A ello hay que añadir que, en el plan de gobierno 2007-2011 del binomio Rafael Correa-Lenin Moreno presentado por Alianza País se plantean cinco "ejes programáticos para la transformación radical del Ecuador" uno de los cuales es "la revolución educativa y de salud" (Alianza País, 2006).

En esa propuesta se propone impulsar la "construcción de una política educativa para la era del conocimiento y la información". Allí se señala que:

Una educación de calidad para todos y todas y a lo largo de la vida, implica una reforma permanente y profunda del aparato educativo, la cual será viable siempre y cuando se promueva el desarrollo del pensamiento complejo, la investigación transdisciplinaria y la incorporación selectiva, pero firme, de las tecnologías de información en las que se mueve y se moverá el mundo. La educación se constituirá en la piedra angular sobre la cual se sustentará nuestro compromiso de alcanzar el desarrollo humano integral. (Alianza País, 2006, p. 44)

Esta declaración, de hecho, habla de recoger algunas propuestas internacionales que podrían permitir una reforma pero nunca una revolución. Se acompaña con algunos articulados que plantean como elemento básico: 
Continuar el desarrollo de una educación básica de calidad para todos y todas, gratuito, articulada con los programas de salud, nutrición y producción, dando énfasis a las zonas rurales y urbanas marginales, en el marco del respecto a la diversidad, interculturalidad y creación permanente de una ciudadanía activa para la construcción de una democracia. (op. cit., p. 44-45)

Llama la atención que para la fecha de presentación de este documento se hable de "continuar" cuando, como hemos visto que ni la educación básica era de calidad, ni para todos y todas, ni gratuita. Lo demás son declaraciones recogidas de Educación Para Todos y el anuncio de "la mejora de los ingresos de los maestros asociadas a logros educativos" (Alianza País, op. cit., p. 45), una vieja propuesta mediante la cual "el neoliberalismo privatiza todo, inclusive el éxito y el fracaso social. Ambos pasan a ser considerados variables dependientes de un conjunto de opciones individuales a través de las cuales las personas juegan día a día su destino, como en un juego de bacará" (Gentili, 2006, p. 22).

\section{La nueva constitución y las nuevas definiciones sociales}

Uno de los compromisos del nuevo gobierno fue el desarrollo de una Asamblea Nacional Constituyente que permitiese iniciar la reconstrucción del Estado con criterios que respondan a la voluntad popular mayoritaria, pues la Constitución anterior (1998) incorporaba en su texto varios principios neoliberales. No sin dificultades, pero con el apoyo de las organizaciones políticas del centro hacia la izquierda y de la gran mayoría de las organizaciones populares, se logró dar paso al desarrollo de la Asamblea Nacional Constituyente, que se realizó en la ciudad en Montecristi, entre el 30 de noviembre de 2007 y el 25 de julio de 2008.

El debate y la movilización social en torno a esta asamblea fueron muy elevados y reflejo de las concepciones de las distintas clases sociales existentes en el país. La mayoría de asambleístas, pertenecientes a las fuerzas democráticas, lograron una Constitución que es reconocida como "garantista de derechos" y reflejo de un "nuevo constitucionalismo".

La Constitución fue aprobada mediante un referendo constitucional que se realizó el 28 de septiembre de 2008, en el cual el 63.93\% de los ciudadanos votó favorablemente y un $28.10 \%$ en contra de la aprobación de la nueva carta constitucional. Así se decidió que entraría en vigencia el 20 de octubre de 2008.

Uno de los aspectos más importantes está en el hecho de que se plantea una alta participación social en torno a un nuevo régimen de desarrollo, el Sumak Kawsay o Buen Vivir, el mismo que habla de la equidad y de la adecuada convivencia entre los seres humanos y entre la sociedad y la naturaleza, impulsando criterios de solidaridad colectiva por encima de los señalamientos neoliberales (Ecuador, 2008). 
El Sumak Kawsay, al igual que la definición de estado plurinacional, continúa como una propuesta a la que hay que llenar de contenido, reconociendo los saberes ancestrales andinos pero también determinando con mayor precisión su alcance y expresiones en la vida social.

En cuanto a la educación, el texto constitucional plantea, entre otros aspectos:

- La educación es un derecho de las personas a lo largo de su vida y un deber ineludible e inexcusable del Estado. Constituye un área prioritaria de la política pública y de la inversión estatal, garantía de la igualdad e inclusión social y condición indispensable para el buen vivir. Las personas, las familias y la sociedad tienen el derecho y la responsabilidad de participar en el proceso educativo (art. 26).

- La educación se centrará en el ser humano y deberá garantizar su desarrollo holístico, el respeto a los derechos humanos, a un medio ambiente sustentable y a la democracia; obligatoria, intercultural, incluyente y diversa; impulsará la equidad de género, la justicia, la solidaridad y la paz; (...) es indispensable para el conocimiento, el ejercicio de los derechos, la construcción de un país soberano y es un eje estratégico para el desarrollo nacional (art. 27).

- La educación responderá al interés público y no estará al servicio de intereses individuales y corporativos. Se garantizará el acceso universal, permanencia, movilidad y egreso sin discriminación alguna y la obligatoriedad en el nivel inicial, básico y bachillerato o su equivalente (art. 28).

- La educación pública será universal y laica en todos sus niveles, gratuita hasta el tercer nivel de educación superior inclusive (art. 28).

- El Estado garantizará la libertad de enseñanza y cátedra y el derecho de las personas de aprender en su propia lengua y ámbito cultural (art. 29).

- La educación como servicio público se prestará a través de instituciones públicas, fiscomisionales y particulares (art. 345).

- Existirá una institución pública, con autonomía, de evaluación integral interna y externa que promueva la calidad de la educación (art. 346).

- El Estado garantizará al personal docente en todos los niveles y modalidades, estabilidad, formación continua, mejoramiento pedagógico y académico, y actualización, una remuneración justa, de acuerdo a la profesionalización, desempeño y méritos académicos. La ley regulará la carrera docente y escalafón, establecerá un sistema nacional de evaluación de desempeño y la política salarial en todos los niveles. Se establecerán políticas de promoción, movilidad y alternancia docente (art. 349). 
Estos y otros artículos recogen en gran medida las demandas que por mucho tiempo habían planteado maestros, padres de familia y estudiantes, a pesar de que existen también algunas consideraciones opuestas a esa historia de lucha, que probablemente se expresaron más en torno a derechos de carácter laboral y sindical. De manera conjunta, la Unión Nacional de Educadores (UNE), la Federación de Estudiantes Secundarios del Ecuador (FESE), la Federación de Técnicos Docentes del Ministerio, la Asociación de Rectores y de Directores de Escuela, la Asociación de Facultades de Filosofía y Ciencias de la Educación, educadores populares y otros llevaron a cabo del 23 al 27 abril de 2007 el Segundo Congreso Nacional de la Educación Pública. En ese evento se aprobó el mandato: “Educar para la libertad, educar para la Patria Nueva" (UnE-MEc, 2007), que en buena medida se refleja en los principios constitucionales.

\section{La tensión entre avances y retrocesos}

El primer período de gobierno de Rafael Correa se inició el 15 de enero de 2007 y avanza con el desarrollo de una serie importante de propuestas, que le ganaron un amplio apoyo social. Eso no quiere decir que no hayan existido dificultades, pero hay una profunda diferencia con el segundo período de gobierno, iniciado tras la aprobación de la nueva Constitución a partir del 10 de agosto de 2009. En muchos análisis que señalan un proceso de derechización del gobierno, ligado a su centralidad económica en las actividades extractivistas al servicio del mercado internacional, contrarias al Sumak Kawsay, que vienen acompañadas de un fortalecimiento de las posiciones autoritarias y de la criminalización de la protesta social (Moreano, 2010; Varios autores, 2010; además de los manifiestos de la mayoría de organizaciones populares en torno a la consulta popular realizada el 7 de mayo de este año). Una parte importante de quienes fueron considerados ideólogos del movimiento político que acompaña al Presidente, hoy se encuentran separados y en oposición a los aspectos en los cuales se considera que hay una traición a los mandatos constitucionales (Alberto Acosta, 2011; Darquea, 2011; Vega, 2011).

Los cuestionamientos y señalamientos de derechización del régimen abarcan desde la economía, pasando por los cambios ideológicos políticos y llegando a la presencia de múltiples denuncias de corrupción y una justicia básicamente controlada desde el poder ejecutivo. No es éste un texto para analizarlo pero podría decirse que el resumen lo hizo el propio presidente Rafael Correa durante la visita de Hillary Clinton, cuando expresó que representa a una nueva izquierda que "no es anti nada, no es anticapitalista ni antiimperialista" (Correa, 2010).

Retomando los aspectos destacables de los primeros años, hay que valorar el importante incremento de la inversión social como porcentaje del pIB, el que tiene 
como un primer factor enorme crecimiento de los ingresos estatales gracias al precio del petróleo, principal producto de exportación del Ecuador y también de una decisión gubernamental de reducir el peso de la deuda externa en el presupuesto del Estado. La inversión social pasó del 4,8\% del PIB en el año 2006 al 8,1\% en el 2009 y se espera que llegue a un 7,9\% en el 2010 (Ponce, Juan y Acosta, 2010).

Adicionalmente, en 2006 la inversión social representaba 0.35 veces del servicio de la deuda externa, mientras en 2009 pasó a ser 2,63 veces más que el servicio de la deuda (idem, ibid.).

En el componente educación del presupuesto, no se ha cumplido íntegramente con el mandato constitucional que señala un incremento del $0,5 \%$ anual hasta llegar, por lo menos, 6\% del Рів. En el presupuesto de 2011, para la Educación General Básica se pasa del 4,1\% al 4,3\% del PIB, mientras para educación superior se descendió del 1,8\% del piв en 2010 a 1,6\% del pів presupuestado para 2011 (Reyes, 2011).

En educación los nuevos recursos permitieron la eliminación del cobro a los padres de familia de un aporte calificado de "voluntario" pero que actuaba como una matrícula obligatoria de 25 dólares en los establecimientos públicos, con lo que miles de niños, niñas y adolescentes quedaban fuera del sistema educativo. A esta decisión, sobre todo en las zonas urbanas marginales, se suma el aumento de escuelas públicas beneficiadas de los desayunos y almuerzos escolares, aunque el año pasado se elimina el almuerzo para ofrecer un "desayuno reforzado". Se entregaron igualmente uniformes gratuitos a los estudiantes de las escuelas rurales y textos escolares acerca de 3 millones de alumnos de la educación general básica.

La matrícula pagada había sido una barrera para el acceso al derecho educativo y su eliminación trajo consigo el incremento de la cobertura educativa, pasando del 90\% en el 2000 al 93\% de niños que se matriculan en la escuela en el 2009; pero apenas el 54\% de jóvenes lo hacen en bachillerato (Contrato Social por la Educación, 2011). Sin embargo de estos avances, las tasas de matriculación distan aún de las propuestas del Plan Decenal de Educación. Así, para educación general básica la matrícula de diez años es del $50 \%$ frente al objetivo del $100 \%$, y, para bachillerato, es de $54,8 \%$ frente al 75\% de meta para 2015 (Ministerio de Educación, 2009). La principal causa, continúa siendo la falta de recursos económicos en las familias (INEC, 2009).

Estos avances contrastan con factores de conflicto que se mantienen. El primero se presentó porque, a pesar de la decisión anunciada al país de entregar nombramiento a 12.000 docentes con base en partidas creadas en el año 2007, la mayoría continuaban en calidad de maestros contratados, muchos en condiciones de trabajo precario; el no haber reabierto 5.000 escuelas públicas cerradas y mantener 6.800 escuelas unidocentes, esto es con un solo maestro para siete grados de educación básica; los continuos retrasos en la entrega de los $\$ 25$ de matrícula por alumno para 
que los establecimientos educativos puedan hacer mantenimiento básico y pago de servicios indispensables; la evaluación docente con carácter punitivo sin cumplir el mandato constitucional que señalaba que debía ser realizada por una entidad autónoma; resurgimiento de mecanismos de evaluación estudiantil e institucional utilizados para desprestigiar a los maestros de educación pública; entre otros aspectos (UNE, 2009).

En esos días el Ministro declaraba al Ecuador "patria alfabetizada" (8 de septiembre de 2009), debiendo más adelante retractarse ya que las estadísticas demostraban que faltaba mucho trabajo para lograr ese propósito y que haber enviado a los estudiantes sin ninguna planificación, capacitación y materiales a realizar una supuesta alfabetización general, había tenido una enorme cantidad de errores y falsedades (Ponce, Juan y Onofa, 2009).

En conjunto, esto llevó al desarrollo de un paro del magisterio organizado en la UNE, logrando importantes victorias gremiales (Isch López, 2010) y negando el intento de crear otra organización de maestros, a la cual llamó el Presidente de la República, mientras el diario oficial El Telégrafo (27 enero 2009) llegó a hablar de 40.000 afiliados al "nuevo gremio" sin que esto se concretara en la práctica y produjera una derrota política del régimen. Sin embargo, desde el gobierno se impulsarían juicios contra un importante número de dirigentes del magisterio y otras organizaciones sociales, llegando a acusar por "terrorismo" y "sabotaje" a 286 dirigentes (Cano, 2010), todos de extracción popular, haciendo uso de normas establecidas por la última dictadura militar y que nunca habían sido empleadas por un gobierno constitucional en el Ecuador.

Los mecanismos de evaluación, en todo caso, retornaron a los procedimientos estandarizados que desconocen la diversidad de condiciones y de sectores sociales ecuatorianos. Esto es más grave si se considera que "las inequidades más grandes encuentran entre alumnos de diferentes niveles socio-económicos" y que "los alumnos de etnias minoritarias también continúan en desventaja" (Grupo FARo, 2010). El Sistema Nacional de Evaluación y Rendición de Cuentas (SER) ha procurado evaluar exclusivamente a maestros y estudiantes, resaltando siempre una supuesta superioridad de la educación privada. Su utilización, sin embargo, ha significado el uso de otro tipo de instrumentos de segregación, entre los cuales a fines de 2010 estuvo el proceso de matrícula en octavo año de educación general básica sólo para los que tenían altas calificaciones, relegando a quienes no las tenían, sin considerar en absoluto las razones que, por ejemplo llevan a tener calificaciones menores a los niños que trabajan en media jornada.

Al momento se inicia la aplicación de estándares educativos, realizados con un nivel de apresuramiento antes de que se conforme el organismo autónomo que señala la Constitución de la República. 
En términos de calidad, el gobierno resalta algunos hechos (El Ciudadano, 2011) que suman cuestionamientos a los realizados por la falta de una propuesta educativa integral al término de cuatro años de gobierno. Entre los factores que se acostumbran mencionar de parte de las autoridades están:

- Una propuesta del nuevo bachillerato considerada inconveniente por distintas instituciones por su "inconsistencia, improvisación, arbitrariedad, incoherencia"... "La propuesta desbarata la "Educación para la Democracia", deforma la enseñanza de Cívica y suprime la Educación Ambiental y la Realidad Nacional. Ni menciona la Patria, ni los valores de la ecuatorianidad, ni la integración andina y sudamericana" (Universidad Andina "Simón Bolívar", 2011). "En la propuesta del Bachillerato General Unificado, la educación está planteada como un entrenamiento para hacer cosas y no para pensar ni discernir" señala el rector Enrique Ayala (La Hora, 2011).

- El llamado Fortalecimiento del Currículo de la Educación General Básica, que fundamentalmente es una adecuación de los contenidos existentes desde 1996 y que se orientan por el logro de "destrezas con criterio de desempeño", mientras en el bachillerato, según la variedad del mismo, se trabaja por competencias o por desarrollo de capacidades humanas. No hay un cambio curricular real en el proceso.

- Continuidad de la gratuidad de la enseñanza, logro que se debilita ante denuncias de cobros a los padres de familia.

- Las "escuelas del milenio", que serán una por provincia, dotadas con la más alta tecnología, mientras hay escuelas que literalmente se caen sobre sus alumnos. Para 2009 se evaluó la infraestructura escolar del país en 3,3 puntos sobre 10 (Expreso, 2009).

- El proyecto de "Bachillerato Internacional", para el cual se seleccionó 17 colegios públicos a los que se fragmentó en dos bachilleratos, siempre menospreciando a la educación nacional (Isch López, 2008b).

Como se puede concluir, se trabaja por proyectos aislados, atendiendo la excepción y no la generalidad, con lo que el Estado construye nuevas formas de discriminación educativa, todas bajo el impulso de una meritocracia que, en el caso de los docentes, estará reflejado en los "estímulos por rendimiento".

Un reciente estudio confirma este señalamiento: “De hecho, la construcción de una política pública integral e integrada de educación para jóvenes y adultos está en ciernes, al igual que la formulación de una política pública que aborde sostenidamente el rezago educativo donde están la niñez, la adolescencia, la juventud y la población adulta" (Amaluisa, 2011, p. 18). 


\section{La nueva Ley de Educación: un resultado que no termina el debate}

La reciente aprobación de la Ley de Educación ha sido, en términos generales, un resultado positivo para reestructurar el sistema educativo nacional, tan debilitado por la aplicación de las recetas neoliberales y proyectos parciales y excluyentes, como los que hemos referido.

Reordenar el sistema debería ser uno de los objetivos de una propuesta educativa integral que pueda en algo justificar el indiscriminado uso de la frase "revolución educativa". Sin embargo, el propio debate de la Ley demostró que el gobierno no tiene la visión integradora de un proyecto educativo nacional. Eso contrario a la UNE y otros sectores ligados a la educación, que plantearon la propuesta de "Educación para la Emancipación" (UNE, 2008).

La propuesta emancipadora y la activa movilización del magisterio, estudiantado, nacionalidades indígenas y padres de familia, dio paso a algunos aspectos positivos de política educativa y reivindicaciones que deben ser resaltados porque vencieron la prepotencia del gobierno y su mayoría en la Asamblea Legislativa. Reseñemos brevemente algunos de esos aspectos:

- $\quad$ El propio nombre de la Ley, pues se logró que se la considere Ley Orgánica de Educación Intercultural, cuando en la propuesta del gobierno no se consideraba el carácter plurinacional e intercultural del Estado;

- los principios y fines vienen de la propuesta de la UNE, aunque ellos trataron de ser burlados con el veto del Presidente Correa y son opuestos a toda la educación competitiva y generadora de mano de obra para las empresas capitalistas impulsada por el nuevo bachillerato;

- $\quad$ se impone el carnet y la tarifa estudiantil con validez de año calendario (en su veto Correa quiso reducirlo al año lectivo) y se reconoce el derecho estudiantil a la libre organización, a pesar de que el gobierno continúa su ataque a las organizaciones populares;

- se reconoce el derecho docente al desarrollo profesional, capacitación, actualización, mejoramiento pedagógico y académico de manera gratuita; y la habilitación para efecto de escalafón de los tiempos de servicios en cualquier plantel educativo o en otras instituciones públicas;

- se garantiza la participación en el Consejo Nacional de Educación de cuatro delegados del magisterio nacional, tres de los estudiantes, uno de las nacionalidades y uno de los pueblos montubios y afro ecuatorianos, venciendo la intención del gobierno de desconocer a las organizaciones nacionales; 
- se formarán los consejos comunales educativos y participativos, a modo del "Gobierno Escolar" planteado por la UnE;

- se reconoce al sistema de educación intercultural bilingüe, que es una conquista histórica de las nacionalidades indígenas;

- la carrera magisterial tendrá diez categorías de escalafón con un sistema integral de ascensos, frente a las cuatro planteadas de manera simplista en la propuesta gubernamental, que no entendía las características específicas de la labor docente;

- en esa carrera hay mejoras salariales que son sustanciales, incluyendo conquistas como el bono por el Día del Maestro que quiso ser negado por el gobierno.

La lista de aspectos positivos es más larga. Sin embargo, el presidente Correa planteó un veto regresivo. El aspecto más difundido de ese veto fue la pretensión de anular el laicismo y disponer la educación religiosa en todos los establecimientos públicos, colocando los recursos del Estado a favor de una sola fe religiosa, cuando desde la revolución liberal de Eloy Alfaro (1895) se había logrado separar al Estado de las iglesias. Este planteamiento no fue aceptado por la mayoría de asambleístas, sin embargo, no es la primera de estas medidas dado que el 12 de junio de 2009 se emitió el Decreto Ejecutivo 1780 mediante el cual el Presidente entregó a la Iglesia Católica grandes apoyos estatales para que, entre otras cosas se encargue del: "Fortalecimiento, de las culturas, evangelización e incorporación a la vida socioeconómica del país de todos los grupos humanos que habitan o habitaren dentro de la jurisdicción territorial encomendada a su cuidado (...)" (Registro Oficial, 2009a). Texto mediante el cual Rafael Correa renunció a la condición de Estado laico y, en los hechos, entregó la soberanía de un territorio que abarca más de la mitad del país. Unos meses más tarde se reformo este decreto, con más cuidado en las palabras pero con las mismas intenciones (Registro Oficial, 2009b).

La Constitución señala la obligatoriedad de evaluar al sistema educativo. Con el veto presidencial, se planteó que el instituto autónomo no pueda evaluar a las autoridades educativas, empezando por el ministro/a de turno, pero Correa tampoco logró los votos en la Asamblea.

Otro aspecto del veto, que se planteó directamente contra las conquistas escalafonarias y salariales, presentándolo como un aspecto solo de forma, ligaba el sueldo actual con el título del magisterio, perjudicando al 70\% del magisterio. En los casos de quienes tienen el título de profesor y no el de licenciado en educación, ello significaba incluso un intento de reducción del sueldo actual, contrario a la misma Ley y al principio universal de irrenunciabilidad a una conquista ganada. 
Como se ve, artículo por artículo grafican dos maneras de entender la educación y falta mucho para vencer las perspectivas conservadoras y elitistas presentes en el gobierno. La disputa entonces se plantea desde la visión total de la educación, hasta los aspectos específicos que dicen como se la lleva. Y esa disputa enfrenta, por tanto, a la organización y movilización popular contra el autoritarismo de un gobierno que se define como derechista en los hechos y demagogo en el discurso.

Este enfrentamiento ha generado, como hemos visto, logros y éxitos para la educación popular, pero también plantea temas en los que hay mucho debate por realizar. Para el veto a la Ley, Correa no logró la mayoría en la Asamblea, lo cual se expresó en el mantenimiento de aspectos importantes como los señalados, pero sin mayoría a favor y solo "por imperio de la Ley" al concluir el plazo legal, también resultó en el ingreso de 37 artículos propuestos en el veto, algunos importantes como:

- Cambio en la sanción de suspensión temporal por destitución inmediata que tendrán los docentes que han fallado la evaluación por dos veces consecutivas; además, con el pretexto de corregir un error tipográfico, aumenta 10 días (medio mes) sin sueldo a la suspensión temporal a quienes reciban esa sanción.

- Aumenta la jornada de trabajo cambiando 40 horas semanales pedagógicas por 40 horas semanales reloj (la diferencia es de 10 horas reloj, es decir más de un día laboral), desconociendo las condiciones específicas que se reconocen internacionalmente a la labor docente, que corresponde a un trabajo intelectual altamente desgastante, el que no puede equipararse mecánicamente con otros períodos de acción laboral; ese trabajo extra demandado, no tiene un correlato salarial correspondiente.

- En las juntas distritales de resolución de conflictos se impone que será la autoridad ministerial quien nombrará a sus integrantes, borrando las exigencias profesionales que se habían determinado e impidiendo selecciones democráticas y con vigilancia ciudadana.

- Termina con la autonomía del Instituto Nacional de Evaluación, contrariando la Constitución Política, al determinar que su junta directiva estará compuesta por tres miembros, todos del Poder Ejecutivo.

- El veto desconoce los derechos de miles de educadores comunitarios manteniéndolos solo bajo régimen de contratos, negándoles el derecho a un nombramiento tras años de trabajar en pésimas condiciones.

- Contra los estudiantes, en el veto de Correa se encuentra todo un capítulo de sanciones que confunden "régimen disciplinario" con represión y ello, 
es desde hace mucho rechazado en términos educativos por antipedagógico y denunciado en términos sociales por antidemocrático. Además, genera la figura de "conmoción interna" que sin duda es sacada de la Ley de Seguridad Nacional de la dictadura militar, para establecer sanción a estudiantes "mientras termina la investigación", rompiendo la presunción de inocencia que marca la Constitución.

\section{Una difícil continuación}

El camino a seguir para la transformación educativa en el Ecuador tiene aún un largo trecho que recorrer. En su transcurso, estarán en juego las visiones e intereses de cada clase social, que mantienen a la temática educativa en la palestra del debate nacional. De hecho, ya se plantean reformas a la Ley recientemente aprobada y aspectos complementarios, así como sobre los proyectos en proceso. Solo el tiempo nos dirá que posición logra más fortaleza y si el gobierno de la llamada "revolución ciudadana" cumple o no con los mandatos constitucionales.

\section{Referencias}

AMALUISA FIALLOS, C. Rezago educativo: barrera a vencer para el buen vivir. Quito: Contrato Social por la Educación, 2011. (Cuadernos del Contrato Social por la Educación, n. 6).

ALIANZA PAÍS. Plan de gobierno 2007-2011 del binomio Rafael Correa-Lenin Moreno. 2006. Disponible en: <http://es.scribd.com/doc/31619413/Plan-de-Gobierno-AlianzaPAIS>

APRENDO. Resultados nacionales de la aplicación de las pruebas aprendo 1996 (redes CEM del EB/PRODEC). Quito: Ministerio de Educación y Cultura, 1998.

APRENDO. Resultados nacionales de la aplicación de las pruebas aprendo 2000 (redes CEM del EB/PRODEC). Quito, Ministerio de Educación y Cultura, 2000.

BANCO MUNDIAL. Evaluación final de EB/PRODEC. 2000.

CANO, J. Terrorismo made in Ecuador. Revista Vanguardia, Quito, n. 267, nov. 2010.

CARE INTERNACIONAL. Hacia un pacto social fiscal por la educación, la salud y la inclusión social. Quito, jun. 2008.

CONTRATO SOCIAL POR LA EDUCACIÓN. Indicadores educativos del Ecuador. 2011. Disponible en: <http://www.contratosocialecuador.org.ec> 
CORREA, R. Video. 2010. Disponible en: <http://www.youtube.com/watch?v=xProShvE5s>

DARQUEA, G. Carta abierta a la militancia de movimiento país. 2011. (mimeo.).

ECUADOR. ASAMBLEA NACIONAL. Ley Orgánica de Educación Intercultural. 2011. Disponible en: <www.asambleanacional.gov.ec $>$

ECUADOR. Constitución de la República del Ecuador; publicada en el registro oficial de 20 oct. Quito, 2008.

EL CIUDADANO. 2010, año de la revolución educativa. El ciudadano.gob.ec,( periódico digital del gobierno de la revolución ciudadana), 14 ene. 2011.

ESTÉVEZ PÉREZ, S. Destrucción de la enseñanza científica. Quito: Causa Proletaria; MIR, 2010.

EXPRESO. Educación tiene 3, 3 sobre 10 en infraestructura y equipos. Diario Expreso, Guayaquil, Ecuador, 11 feb. 2009.

FLACSO. Desafíos de la educación en el Ecuador: calidad y equidad. Carlos Arcos Cabrera y Betty Espinoza (Coord.). Quito, mayo 2008.

GENTILI, P. Neoliberalismo e educação: manual do usuário. In: SiLva, T.T.; GeNTILI, P. (Org.). Escola S.A.: quem ganha e quem perde no mercado educacional do neoliberalismo. Brasília, DF: CNTE, 1996.

GRUPO FARO. Informe de progreso educativo Ecuador: ¿Cambio educativo o educación por el cambio? Quito: Grupo Faro; PREAL; Fundación Ecuador, 2010. Disponible en: $<$ http://www.educacion.gov.ec/>

INEC. EMENDU. Instituto Nacional de Estadísticas y Censos. Quito, 2008.

INSTITUTO NACIONAL DE ESTADÍSTICAS Y CENSOS (INEC). Ecuador en cifras 2009. Disponible en: <http://www.inec.gov.ec/web/guest/inicio>

ISCH LÓPEZ, E. Educación democrática para enfrentar a la educación neoliberal. Quito: Pedagógicas; Ibarra, 2001.

ISCH LÓPEZ, E. вм y вID: deuda para imponer la política neoliberal en educación; comisión para la auditoría integral del crédito público. Quito: Ministerio de Finanzas, 2008a.

ISCH LÓPEZ, E. Bachillerato internacional: ¿alternative o modelo extranjerizante? 2008b. Disponible en: <http://www.voltairenet.org/article156513.html>

ISCH LÓPEZ, E. Apuntes sobre la lucha del magisterio ecuatoriano contra la evaluación estandarizada. Intercambio, México, DF, v. 3, n. 1, jul. 2010. 
LA HORA. El bachillerato unificado bajo lluvia de críticas. Diario La Hora, Quito, 9 mar. 2011.

LUNA TAMAYO, M. La educación en los últimos años en el Ecuador: situación y propuestas., Quito: Contrato social por la educación, 2006. (Cuadernos del Contrato Social por la Educación, n. 4)

ECUADOR. Ministério de Educación. Actualización y fortalecimiento curricular de Educación Básica. Quito, 2009a. Disponible en: <http://www.educacion.gov.ec/pages/ interna_noticias.php?txtCodiNoti=1776>. Aceso en: 25 ago. 2009.

ECUADOR. Ministério de Educación. Rendición de Cuentas - año 2008: otro año de revolución educativa. Quito, 2009b. Disponible en: <http://www.educacion.gov.ec/_ upload/rendicion.pdf>. Aceso en: 25 feb 2009.

ECUADOR. Ministerio de Educación. Ecuador es por ahora "patria alfabetizándose". Quito, 2010a. Disponible en: <http://www.educacion.gov.ec/pages/interna_noticias. php?txtCodiNoti=2133>

ECUADOR. Ministerio de Educación. Nuevo Bachillerato Ecuatoriano, versión preliminar. Quito, 2010b. Disponible en: <www.bachillerato.ecuatoriano.gov.ec>

ECUADOR. Ministerio de Educación y Cultura. Plan decenal de educación 2006-2015. Quito, 2006. Disponible en: <http://www.educacion.gov.ec/_upload/PlanDecenaldeEducacion.pdf>

MOREANO, A. Necesitamos redefinir un proyecto de sociedad. In: FUNDACIÓN ROSA LUXEMBURG. Democracia participación y socialismo: Bolivia-Ecuador-Venezuela. Quito, 2010.

PONCE, J.; ACOSTA, A. La pobreza en la "revolución ciudadana" o ipobreza de revolución? Quito: FLACso, 2010. (mimeo.).

PONCE, J.; ONOFA, M. Alfabetización en el Ecuador: evolución histórica, información actualizada y mapa nacional del analfabetismo, 2009. Quito: Unesco; Ministerio de Educación, 2009.

REGISTRO OFICIAL. Decreto Ejecutivo 1780. Quito, Jueves, 25 jun. 2009a.

REGISTRO OFICIAL. Decreto Ejecutivo 15. Quito, Jueves, 25 jun. 2009b.

REYES, G. ¿Hacia dónde marcha la economía ecuatoriana en el año 2011?. Rupturas: Revista de investigación, análisis y opinión, Quito, n. 2, ene. 2011.

UNIÓN NACIONAL DE EDUCADORES. Propuesta de Educación para La emancipación. Quito: El Educador, 2008. 
UNIÓN NACIONAL DE EDUCADORES. Posición de la uNE frente a la problemática educativa del país. Quito, 2009.

UNIÓN NACIONAL DE EDUCADORES. Resoluciones del segundo Congreso Nacional de la educación pública y mandato para la asamblea constituyente. Quito: UNE/ME, 2007.

UNICEF. ¿Qué país y que educación quieren los ecuatorianos?: Apuntes para un debate nacional. Quito, 2006.

UNIVERSIDAD ANDINA SIMÓN BOLÍVAR. Análisis de la propuesta de nuevo bachillerato presentada por el Ministerio de Educación. Área de Educación. Quito, 2011. Disponible en: <www.uasb.edu.ec>

VARIOS AUTORES. 30-S el golpe que no fue: análisis crítico desde la izquierda. Quito: Opción, 2010.

VEGA, F. En camino a la banana republic del siglo xxI:¡A Así no presidente, así no! Cuenca: 2011. (mimeo.).

WORD BANK. Implementation Completion Report. Report n. 21171, Quito, 29 nov. 2000.

Recebido em março de 2011.

Aprovado em junho de 2011. 